\title{
THE EFFECT OF STRATEGIC CHANGE IN ORGANIZATIONAL PERFORMANCE FIELD RESEARCH AT THE OIL PROJECTS COMPANY (SCOP)
}

\author{
Yousif Olaiwe Abdullah Al-Hamdani, Ass.Prof. Faik Jawad Kadhim \\ College of Administration and Economics - Baghdad University
}

DOI: $10.37648 /$ ijrssh.v10i03.026

Received: $18^{\text {th }}$ June, 2020; Accepted: 10th July, 2020; Published: 29th July,2020

\begin{abstract}
This research aims to know the reality of strategic change with its approaches (organizational culture, restructuring, renewal, and modernization) and organizational performance with its two dimensions (efficiency and effectiveness) in the Oil Projects Company (SCOP), which is one of the Iraqi companies in the Ministry of Oil, Its mission is to implement oil projects throughout the country and to contribute to strengthening its economy. The researcher used the questionnaire as the main tool to obtain data that was designed according to Likert pentatonic scale, The research community included the leaders working in the company's center, which there numbered (196) individuals, being the authority responsible for drawing plans, policies and procedures related to strategic change, and the size of the research sample was (85) individuals. The researcher used (mean, standard deviation, Coefficient of variation, relative importance, Pearson coefficient, simple and multiple linear regression) in analyzing the data obtained from the research sample. The results of the study found there is an effect of strategic change in organizational performance and that the nature of the relationship between them is positive. As for the restructuring approach, the results of multiple linear regression showed that the procedures followed in restructuring do not significantly affect performance, which requires a level of greater attention.
\end{abstract}

\section{INTRODUCTION}

The business environment in our world today is characterized by continuous change as a result of developments in various economic, social, political and technological aspects, which made it necessary to make a change in their functions, activities, organizational structures and technologies used to adapt to environmental factors so the strategic change guarantees organizations to achieve success as it makes Business and jobs are more flexible and specialized, in addition to maintaining the quality of the products and services provided, a strength in focusing on the main jobs and attention to expertise, skills, scientific and knowledge aspects. The strategic change is characterized by continuity and inclusiveness in various aspects of life in general and organizations in particular, and because of the limited adoption of such topics and their non-use in Iraqi organizations despite their importance, and for fear of wasting opportunities to benefit from their data, it became necessary to conduct research, study and expansion in order to delve into their ideas and knowledge And extracting the most important indicators to measure 
and apply them to reach the appropriate solutions, therefore this research came to research in an organization in urgent need to improve the level of its performance through strategic approaches focusing on change, namely: "Oil Projects Company (SCOP)" one of the companies affiliated to the Ministry of Oil.

\section{THE FIRST TOPIC: RESEARCH METHODOLOGY}

\section{1-1 The research problem}

The research problem lies in knowing the reality of strategic change and organizational performance in the Oil Projects Company (SCOP).

\section{1-2 The importance of research}

The importance of the research lies in finding appropriate ways and methods at work to improve the level of performance of the Oil Projects Company (SCOP).

\section{1-3 The hypothetical research scheme}

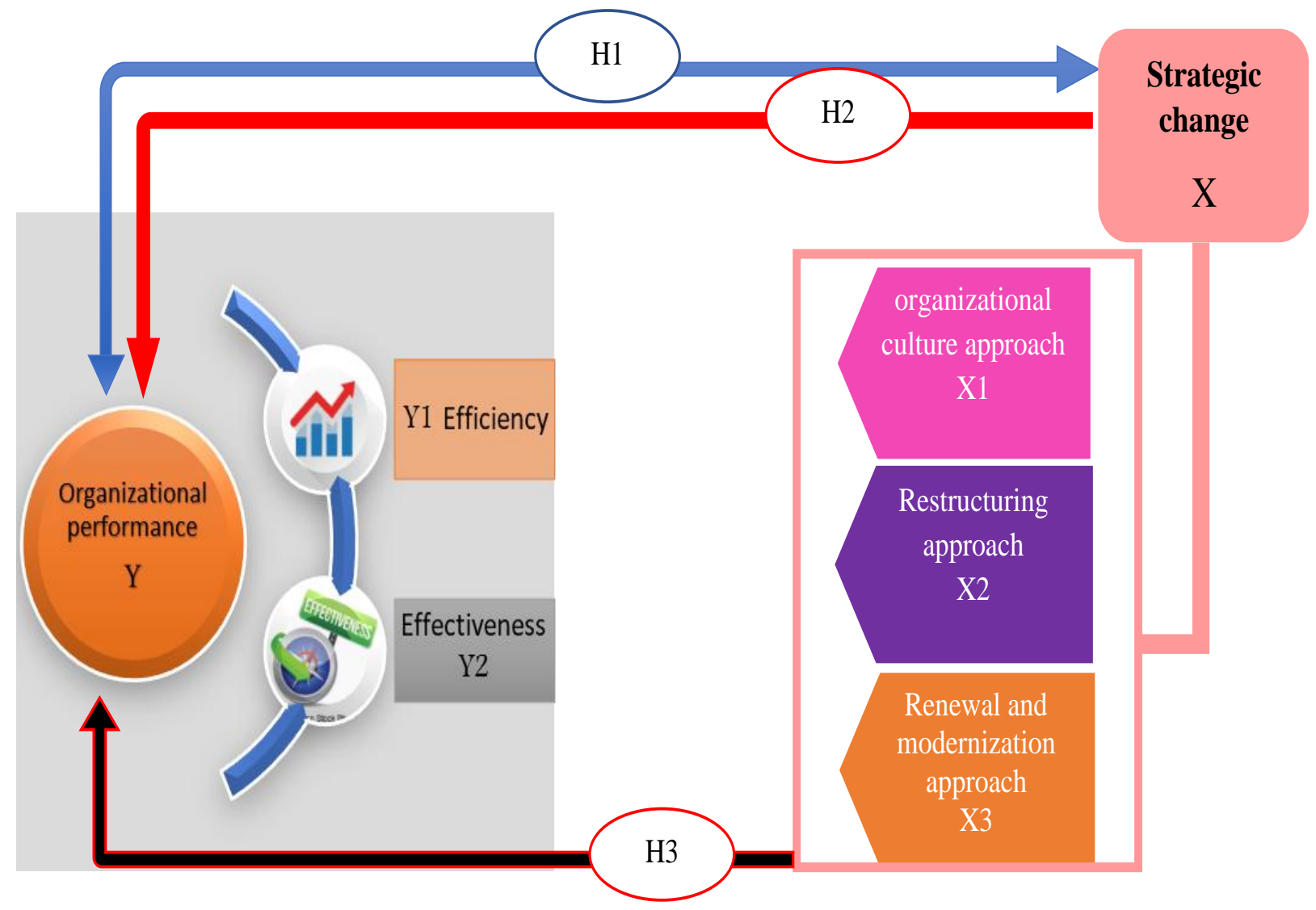

Figure (1) research hypothesis

\section{1-4 Research hypotheses}

$\mathrm{H} 1$ : There is no statistically significant correlation between strategic change (Organizational Culture, restructuring, renewal, and modernization) and organizational performance (Efficiency and effectiveness).

$\mathrm{H} 2$ : There is no statistically significant effect of the strategic change (Organizational culture,
Restructuring, renewal and modernization) in organizational Performance (Efficiency and Effectiveness).

H3: There is no statistically significant effect of the strategic change approaches (Organizational Culture, restructuring, renewal and modernization) in organizational Performance (Efficiency and effectiveness). 


\section{2-1 strategic change}

Strategic change is a prominent feature at the present time as it has received the attention of many studies and scientific research. As for the concept of strategic change, there is no single definition capable of covering all its aspects, given its conceptual nature. (McElroy, 1996) defined strategic change as a change in the organization's culture, in order to design an appropriate implementation strategy, where the organization must be able to define the current and future culture, and (Abbas \& Asghar, 2010) defined strategic change as a change in trends and activities in order to influence the way the organization works, While (Gibbons, 2015) defined strategic change as a change in jobs and organizational structures in order to confront environmental risks and raise the level of organizational performance. As for (Shin, 2019), has been defined the strategic change as a change in the way the organization works with the aim of achieving a competitive advantage. As for the approaches to strategic change, it can be explained as follows:

\section{Organizational culture approach}

Since the late thirties of the last century, organizations began to pay attention to development, and in the forties, trends emerged in organizational research relevant to sociologists such as (Max Weber, Talcott Parsons), Where they defined the organization as a structural system for teamwork, and it has values and goals and is affected in the surrounding environment (Muscalu, 2014). (Maull, et al, 2001) classified the concept of organizational culture into three levels:

1. There are multiple models of organizational culture that illustrate the way in which Functions and activities are implemented within the organization.

2. Organizational culture is an integrated system of values and beliefs that all members of the Organization share.

3. A program that defines style and way of thinking. (Robbins: 2003) showed that organizational culture has certain characteristics through which it reflects the level of interest in creativity and carries risk and focus on results regardless of the methods and means used, and the level of focus on teams, and main functions. Lack of interest in changing organizational culture is an obstacle to the success of the change process, as organizations cannot continue with the same culture pattern as a result of environmental developments ( Muscalu, 2014), As for (Mats and Stephan, 2008), he showed that organizational culture has values and beliefs that are deeply rooted in the organization, Therefore, it is not easy to change the organizational culture, and the necessary conditions must be created for the success of the change process (Alvesson \& Sveningsson, 2008).The change in the organization's vision, tasks, goals and the need to adopt new working methods and change the method of employment and conflicts between individuals make organizations realize the need to make a change in organizational culture (Muscalu, 2014), In order to achieve the success of the process of changing the organizational culture, (Barsade \& Bernstein, 2016) outlined five steps:

1. Knowing the current culture site which gives a real picture of the required change size.

2. Ensuring from the appropriateness of the cultural change to the organization's strategy, Policies, and structures.

3. Stakeholder participation by providing ideas and solutions, participating in decisions, and Preventing a delay in procedures.

4. Communicating the future vision to give a clear picture of what the organization will look Like.

5. Managing emotional response appropriately, and developing contingency plans to counter Potential resistance to change that naturally arises in some critical aspects of changing Organizational culture.

\section{Restructuring approach}

The researchers and writers differed in the definition of restructuring, as a result of the bifurcation in this concept and the lack of an integrated intellectual vision covering all aspects that are related to the topic of restructuring, (Som ,2002) defined restructuring is a process that aims to respond to the surrounding changes, which requires the need to review the design of the organizational structure and programs, organizational strategy, prevailing culture, and technology used, As for (Harwood et al., 2016) they defined restructuring as a change in activities and functions, to make the organization's performance more effective and more capable of achieving its goals, Therefore, the restructuring came as a result of the low level of productivity, the low quality of services provided to clients, the low level of profits, as well as changes in laws and regulations and low growth rates(Kurgat, 2016), In order to achieve success in the restructuring process, it must provide a clear vision of the future that Management of the organization aspire to, set policies according to the specific vision as well as define the role of individuals in this

\section{INTERNATIONAL JOURNAL OF RESEARCH IN SOCIAL SCIENCES AND HUMANITIES}


process, assess the current status of the organization, provide human and material resources, and train staff (Drljca, 2015 ).

\section{Renewal and modernization approach}

This approach is considered one of the most difficult approaches to strategic change, as it needs to provide a supportive environment for innovation and success (Hill, et al, 2014), As for the concept of this approach, (Sharma \& Chrisman 1999) defined innovation and modernization is a set of activities that involve modifying the organization's functions, strategy, and organizational structure to invest the opportunities available in the external environment. (Kusar, 2010) defined it as a process aimed at updating resources and capabilities in order to enhance the effectiveness of the organization, respond to environmental changes, and achieve a competitive advantage for survival and development. (Lampert \& Ahuja, 2001) identified several reasons that required the organization's management to undertake the renewal and modernization process, including: (1) The intensity of the conflict between individuals (2) the lack of experiences and competencies (3) inappropriate methods in the work (4) the emergence of an urgent need to invent new products that meet the desires of customers, achieve a competitive advantage(5) Changes in economic, political, social, and cultural aspects, technical developments, and the emergence of globalization. In order for the organization's administration to ensure success in the renewal and modernization, it must provide communication channels that facilitate the process of transferring information between individuals, taking advantage of expertise and skills, investing available resources, and following the method of understanding between organizations, rather than the simulation method (Rosler,2015).

\section{2-2 Organizational performance}

The concept of organizational performance gained great interest in various fields, given its importance in giving a clear and expressive picture of the reality of the organization through the use of specific criteria for measurement, and as a result of environmental developments, the need arose to improve the performance of organizations, because it is the main means to achieve goals and progress (Elena \& Maria, 2016). Organizational theories presented the idea that an organization achieves its goals by investing its resources (Gavrea, et al, 2011), (Miller \& Bromicly, 1990) defines organizational performance as the way an organization invests its human and financial resources to achieve its goals, and agrees with them (Moda et al, 2014) in defining organizational performance as the results achieved by the organization, by investing resources and within a specific period, (Hokana, 2011) indicated that organizational performance in profit and non-profit organizations includes an appropriate mix of (efficiency and effectiveness), (Mihaiu, Et al., 2010) argued that achieving efficiency requires: (1) the organization's management must divide tasks and duties, (2) focus on continuous training and learning, (3) the need to use technologies that are characterized by sophistication and comprehensive specialization, (4) Attention to research and development in order to increase productivity, reduce costs and achieve a sustainable competitive advantage, (5) adopt appropriate strategies in selection, appointment, and focus on work teams, (6) develop the organization's infrastructure that includes (organizational structure, organizational culture, and leadership style) (Hill and Jones, 2014). (Love \& Skitmore, 1996) Define effectiveness as the organization's ability to achieve its goals by investing its resources. Effective organizations are characterized by their high productivity and quality of services (Bartuseviciene \& Sakalyte, 2013). (Jones and George, 2016) Discuss that organizations that strive to achieve efficiency and effectiveness must have a management that is able to use resources better and direct them towards achieving goals, as organizations are able to be effective in their performance when they invest their resources as inputs efficiently i.e. the relationship between Efficiency and effectiveness is a relationship between input and output.

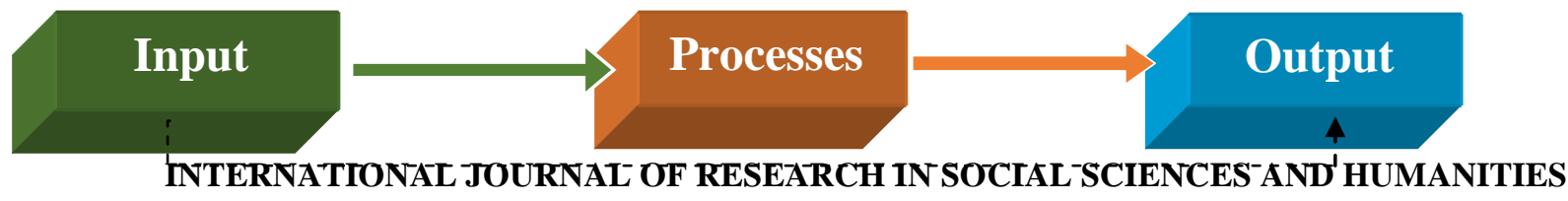


Figure (2) The relationship between efficiency and effectiveness

Source: Mandl, U., Dierx, A. \& Ilzkovitz F. (2008),“ The effectiveness and efficiency of public spending”, : European Commission Directorate-General for Economic and Financial Affairs Publica tions, pp:3

\section{2-3 The relationship between strategic change and} organizational performance

The goal of strategic change is to achieve compatibility between the activities of the organization and its external environment through growth and innovation and meet customer needs in order to maintain the competitive position (Gitonga, 2014). For organizations to achieve a high level of performance, they must make a change in their goals, strategies, and operations (Atieno, 2017) Successful organizations are concerned with strategic change in order to improve their performance (Kamau \& Oloko, 2016), because organizational performance is one of the main criteria that reflects the ability of the organization to achieve efficiency and effectiveness by investing its resources better and this in turn contributes to its survival ( Abdi Khadid\& Rotich, 2017). Since the improving organizational performance depends primarily on compatibility between the organization and its external environment, therefore organizations make the strategic change in response to environmental changes, where strategic change arises from the need for organizations to take advantage of opportunities to meet threats, so it is necessary for senior management make a change in operations And functions that enhance organizational performance. the improving organizational performance depends primarily on compatibility between the organization and its external environment, therefore organizations make the strategic change in response to environmental changes, where strategic change arises from the need for organizations to take advantage of opportunities to meet threats, so it is necessary for senior management make a change in operations And functions that enhance organizational performance (Ntinyari, 2015).

\section{THE THIRD TOPIC - THE PRACTICAL SIDE}

The reality of strategic change and organizational performance in the Oil Projects Company (SCOP) According to the answers of the research sample

Data were obtained from the answers of the research sample on the questionnaire paragraphs that were prepared according to the five-digit Likert scale. The level of each of the research variables is classified by dividing $(4 / 5=0,80)$, Table (1) shows the interpretation of the arithmetic mean.

Table (1) the values of the arithmetic mean and the direction of the answers of The research sample

\begin{tabular}{|c|c|c|}
\hline Arithmetic mean weighted & Scale of answers & The level of answers \\
\hline $1-1.79$ & Strong disagree & Very weak \\
\hline $1.80-2.59$ & Disagree & Weak \\
\hline $2.60-3.39$ & Neutral & Average \\
\hline $3.40-4.19$ & Agreed & Good \\
\hline $4.20-5$ & Strong dgree & Very good \\
\hline
\end{tabular}

\section{3-1 Presenting the reality of strategic change in Oil Projects Company (SCOP)}

Table No. (2) Shows the statistical values that reflect the reality of strategic change in the oil Projects Company (SCOP). The strategic change approaches are arranged according to the coefficient of variance extracted by (Standard deviation/mean * 100). In general, (The Strategic Change)achieved arithmetic mean (3.54), this indicates that the procedures followed in the company 
that relates to this variable are (good), As for the restructuring approach, it achieved arithmetic mean $(3,73)$ and a good level, the standard deviation (0.45), and the coefficient of variance (12.18), This indicates the agreement of the research sample on this approach and the lack of dispersion in the answers, so it achieved (first-order), While the approach (renewal and modernization) achieved arithmetic mean (3.36), at the level (average), and a standard deviation (0.63), and a coefficient of variation $(18,48)$, this indicates a high percentage of dispersion in the answers, so this approach came in the (third-order), Which requires a greater level of attention, Figure (1) shows the arrangement of the strategic change approaches.

Table (2) the level of strategic change in the Oil Projects Company (SCOP)

\begin{tabular}{|l|lll|l|}
\hline Strategic change & $\begin{array}{l}\text { Arithmetic } \\
\text { mean }\end{array}$ & $\begin{array}{l}\text { Standard } \\
\text { deviation }\end{array}$ & $\begin{array}{l}\text { Coefficient of } \\
\text { variation }\end{array}$ & Rank \\
\hline Organizational culture & 3.53 & 0.50 & 14.24 & 2 \\
Restructuring approach & 3.73 & 0.45 & 12.18 & 1 \\
Renovation and modernization approach & 3.36 & 0.63 & 18.84 & 3 \\
Strategic change & 3.54 & 0.46 & 12.94 & \\
\hline
\end{tabular}

Source: According to (SPSS v. 23) program output.

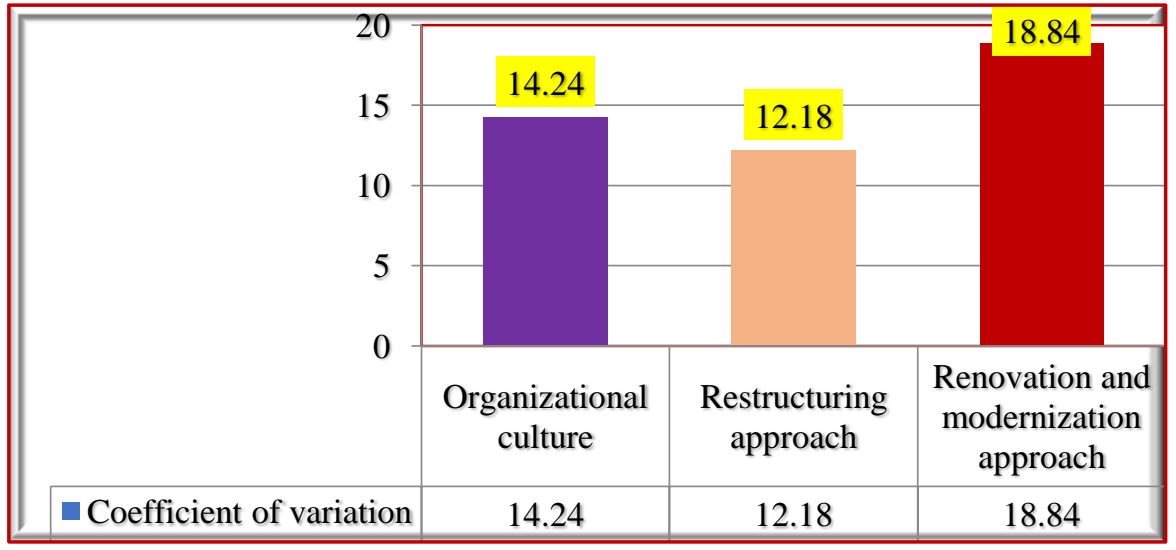

Figure (3): Order strategic change approaches

\section{3-2 The reality of organizational performance in the Oil Projects Company (SCOP)}

Table (3) shows the statistical data for the answers of the research sample, which reflect the level of (organizational performance) in the Oil Projects Company (SCOP). In general, the organizational performance achieved an average mean (3.45), this means that the performance level of the company (good), As for the efficiency, achieved Arithmetic mean (3.28), and this indicates that the efficiency level in the company is (average), and Standard deviation $(0,40)$, and coefficient of variation $(12,03)$, This indicates that the answers of the research sample were the most agreed and the least dispersed, So this dimension came in the ( first-order), Whereas the (effectiveness) dimension achieved a mean (3.62) with a (good) level, a standard deviation $(0,48)$, and Coefficient of variation $(13,23)$, and this indicates a high level of dispersion in the answers, So this dimension came in the ( second-order). Figure (3) shows the order of the organizational performance dimensions.

Table (3) the level of organizational performance in the Oil Projects Company (SCOP) 


\begin{tabular}{l|lcc|l}
\hline & mean & deviation & of variation & \\
\hline Efficiency & 3.28 & 0.40 & 12.03 & $\mathbf{1}$ \\
\hline Effectiveness & 3.62 & 0.48 & 13.23 & $\mathbf{2}$ \\
\hline Organizational performance & 3.45 & 0.41 & 11.73 &
\end{tabular}

Source: According to (SPSS v. 23) program output.

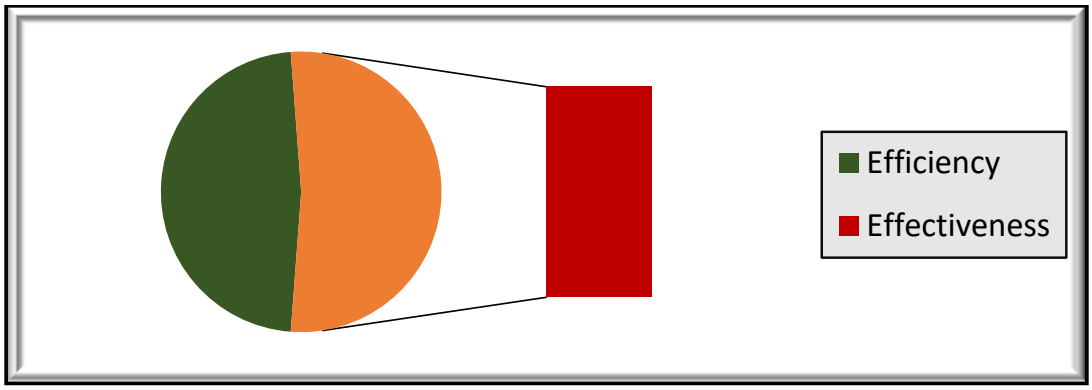

Figure (4): Order of organizational performance dimensions

\section{3-3 Analyze the correlation between strategic change and organizational performance}

The Pearson Correlation coefficient was used to test the first research hypothesis, and Correlation coefficient values range from $\{+1$ to -1$\}$, If the correlation coefficient value is equal to (0), this means that there is no correlation between the variable (X) that represents strategic change, and the variable $(\mathrm{Y})$ that represents the organizational performance, and if the correlation coefficient between the two variables $(\mathrm{X}$ and $\mathrm{Y})$ is $(+1)$ this means that the correlation relationship is positive, and if the correlation coefficient value between the search variables is (-1), this means that the correlation relationship is inverse, When the (**) sign appears on the correlation coefficient values, this means that the correlation relationship is at a significant level (0.01), while if the $\left(^{*}\right)$ sign appears, this correlation relationship is at a significant level (0.05). Table (4) shows that the correlation coefficient values between strategic change and organizational performance ranged between $\left(.518^{* *}\right.$ and $\left..806^{* *}\right)$, This indicates that the correlation relationship between the search variable (X and $\mathrm{Y}$ ) is a relationship ( positive) and at the (significance) (0.00), which is less than a significant level at (0.01) and that the results achieved provide full support through:

Rejection of the null hypothesis:

There is no statistically significant correlation between strategic change (Organizational culture, restructuring, renewal, and modernization) and organizational performance (Efficiency and effectiveness)

\section{Accept the alternative hypothesis:}

There is a statistically significant correlation between strategic change (Organizational culture, restructuring, renewal, and modernization) and organizational performance (Efficiency and effectiveness).

As for the interpretation of this relationship, it means that the strategic change in its entrances (organizational culture, restructuring, renewal and modernization) plays an important role in improving the level of organizational performance.

Table (4) Statistical values of Pearson correlation between strategic change and organizational performance

Strategic change Renewal and Restructuring Organizational Sig




\begin{tabular}{lllll|l}
\hline & modernization & & culture & & \\
\hline $.717^{* * *}$ & $.692^{* *}$ & $.518^{* *}$ & $.622^{* *}$ & Correlation & Efficiency \\
.000 & .000 & .000 & .000 & sig \\
$.771^{* *}$ & $.769^{* *}$ & $.548^{* *}$ & $.645^{* *}$ & Correlation & \\
.000 & .000 & .000 & .000 & sig & Effectiveness \\
$.806^{* *}$ & $.792^{* *}$ & $.576^{* *}$ & $.684^{* *}$ & Correlation & Organizational \\
.000 & .000 & .000 & .000 & sig & performance \\
\hline
\end{tabular}

Source: According to (SPSS v. 23) program output

3-4 Testing and analyzing the impact of strategic change in organizational performance

The effect of strategic change in organizational performance tested according to the simple linear regression equation $(\mathrm{Y}=\beta \mathrm{o}+\beta 1 \mathrm{X}+\epsilon)$, The equation shown below is used to appreciation the model's milestones:

$\widehat{Y}=b_{o}+b_{1} X$

Table (5) shows the presence of a statistically significant effect of the strategic change in organizational performance. The calculated test $(\mathrm{F})$ value was (153.507), which is greater than the tabular $(\mathrm{F})$ value, and with a degree of freedom $(1,83)$ and at the level of significance (0.01) whose value is (6.95), and this indicates a statistically significant impact of strategic change in organizational performance and that the results achieved provide full support through:

\section{Rejecting the null hypothesis:}

There is no statistically significant effect of strategic change "organizational culture, restructuring, renewal and modernization" in organizational performance "efficiency and effectiveness".

\section{Accept the alternative hypothesis:}

There is a statistically significant effect of strategic change "organizational culture, restructuring, renewal and modernization" in organizational performance "efficiency and effectiveness".

Achieved the value of (R2) (0.649), which means that the strategic change affects in the organizational performance by $(65 \%)$ and $(35 \%)$ pointing to a difference in other factors that did not enter the research model, As for the value $\left(b_{o}\right)$ $(0.930)$ it is statistically significant, the value of the (T-test) computed was (4.531), which is greater than (2.37), Which represents the value of tabular ( $\mathrm{t}$ ), with a degree of freedom (83), and at the level of significance (0.01), and this indicates that when the strategic change equal (zero), The organizational performance is not less than this value. The value of $\left(b_{1}\right)$ (0.713), denotes that it is statistically significant, As for the test value $(\mathrm{t})$ calculated (12.390) which is greater than the tabular $(\mathrm{t}) \operatorname{value}(2.37)$, and in the degree of freedom (83), and at the level of significance $(0.01)$, and this means that the increase in strategic change by (one unit) leads to an increase in organizational performance by $(71.3 \%)$.

As for the strategic change approaches (Organizational culture, restructuring, renewal, and modernization), Calculated $(\mathrm{F})$ test value was $(73.157,41.265,139.524)$ respectively, which is greater than the tabular $(\mathrm{F})$ value (6.95), and with a degree of freedom $(1,83)$ and at the level of significance (0.01), and this indicates a statistically significant effect of strategic change approaches in organizational performance. Achieved the value of (R2) $(0.468,0.332,0.627)$, respectively, and this result indicates that the strategic change approach (organizational culture, restructuring, renewal and modernization) achieving a change in organizational performance by $(47 \%, 33 \% 63 \%)$, respectively, while the remaining proportions $(53 \%, 67 \%$, $37 \%)$ Respectively, it indicates the variance in other factors that did not enter the research model.

Table (5) Statistical results of the strategic change effect in organizational performance 


\begin{tabular}{|c|c|c|c|c|c|c|c|c|}
\hline I Sing & (F) test & $\mathrm{R}^{2}$ & Sing & (T) test & \multicolumn{2}{|c|}{$\begin{array}{l}\text { Regression } \\
\text { coefficients }\end{array}$} & $\begin{array}{l}\text { Independent } \\
\text { variable }\end{array}$ & $\begin{array}{l}\text { Dependent } \\
\text { variable }\end{array}$ \\
\hline \multirow[t]{2}{*}{0.000} & 73.157 & .468 & .000 & 6.542 & 1.504 & $b 0$ & \multirow{2}{*}{$\begin{array}{l}\text { Organizational } \\
\text { culture }\end{array}$} & \multirow{8}{*}{$\begin{array}{l}\text { Organizational } \\
\text { performance }\end{array}$} \\
\hline & & & .000 & 8.553 & 0.552 & $b 1$ & & \\
\hline \multirow[t]{2}{*}{0.000} & 41.265 & .332 & .000 & 5.106 & 1.535 & $b 0$ & \multirow[t]{2}{*}{ Restructuring } & \\
\hline & & & .000 & 6.424 & 0.514 & $b 1$ & & \\
\hline \multirow[t]{2}{*}{0.000} & 139.524 & .627 & .000 & 11.934 & 1.750 & $b 0$ & \multirow{2}{*}{$\begin{array}{l}\text { Renewal, and } \\
\text { modernization }\end{array}$} & \\
\hline & & & .000 & 11.812 & 0.507 & $b 1$ & & \\
\hline \multirow[t]{2}{*}{0.000} & 153.507 & .649 & .000 & 4.531 & 0.930 & $b 0$ & strategic change & \\
\hline & & & .000 & 12.390 & 0.713 & $b 1$ & & \\
\hline
\end{tabular}

Source: According to (SPSS v. 23) program output

The third hypothesis defined by the research was tested to see whether it could be accepted or rejected according to the multiple linear regression equation shown below:

$$
\widehat{Y}=b_{0}+b_{1} X_{1}+b_{2} X_{2}+b_{3} X_{3}
$$

Table (6) shows the presence of a statistically significant effect of the strategic change in organizational performance. The calculated $(F)$ test value was $(56,73)$, which is greater than the tabular $(F)$ value $(4,03)$, and with a degree of freedom $(1,83)$ and at the level of significance (0.01), and this indicates a statistically significant impact of strategic change approaches (organizational culture, restructuring, renewal, and modernization) in organizational performance, and that the results achieved provide full support through:

\section{Rejecting the null hypothesis:}

There is no a statistically significant effect of the strategic change approaches (Organizational

Culture, restructuring, renewal, and modernization) in organizational Performance (Efficiency and effectiveness)

\section{Accept the alternative hypothesis:}

There is a statistically significant effect of the strategic change approaches (Organizational Culture, restructuring, renewal, and modernization) in organizational Performance (Efficiency and effectiveness).
Achieved the value of (R2) (0.68), which means that the strategic change approaches affect in the organizational performance by $(68 \%)$ and $(32 \%)$ is a difference in other factors that did not enter the research model, while for the value of (b0) which amounted to (1.20), it is statistically significant, and relative to the value of calculated $(\mathrm{t})(5.37)$, which is greater than tabular ( $\mathrm{t})$ value (2.37) with a degree of freedom (82) and at the level of significance (0.01), with regard to the value $\left(b_{1}\right)$ of (organizational culture, renewal and modernization) it reached (0.20, 0.37), respectively, and it is statistically significant with regard to the calculated $(\mathrm{t})$ value $(2.83,6.40)$, respectively, it is greater than the tabular (t) value (2.37), at the level of significance (0.01), and with a degree of freedom (81), This means that (organizational culture, renewal, and modernization) positively affects in organizational performance, by $(20 \%, 37 \%)$, respectively. The value of ( $b_{1}$ ) of the restructuring approach was (0.08), and it is statistically insignificant, and that the calculated $(\mathrm{t})$ value (1.12) less than the tabular (t) value(1.66) at the level of significance (0.05) and with a degree of freedom (81), this means no effect statistically significant effect in organizational performance. 


\begin{tabular}{|c|c|c|c|c|c|c|c|}
\hline المعنوية & $\mathrm{F}$ & $\mathrm{R}^{2}$ & Sing & $\mathrm{t}$ & B & $\begin{array}{l}\text { Variables } \\
\text { explicativas }\end{array}$ & $\begin{array}{l}\text { Dependent } \\
\text { variable }\end{array}$ \\
\hline \multirow{4}{*}{.000} & \multirow{4}{*}{56.73} & \multirow{4}{*}{0.68} & 0.000 & 5.37 & 1.20 & bo & \multirow{4}{*}{$\begin{array}{l}\text { Organizational } \\
\text { performance }\end{array}$} \\
\hline & & & 0.006 & 2.83 & 0.20 & $\begin{array}{l}\text { Organizational } \\
\text { culture }\end{array}$ & \\
\hline & & & 0.267 & 1.12 & 0.08 & Restructuring & \\
\hline & & & 0.000 & 6.40 & 0.37 & $\begin{array}{l}\text { Renewal, and } \\
\text { modernization }\end{array}$ & \\
\hline
\end{tabular}

Source: According to (SPSS v. 23) program output

It is clear to us through Figure (5) that the (Restructuring approach) was the least influential in performance compared to (Organizational culture, Renewal, and modernization) and this indicates that the quality of the procedures followed in this approach does not significantly affect in organizational performance, which requires a level more attention.

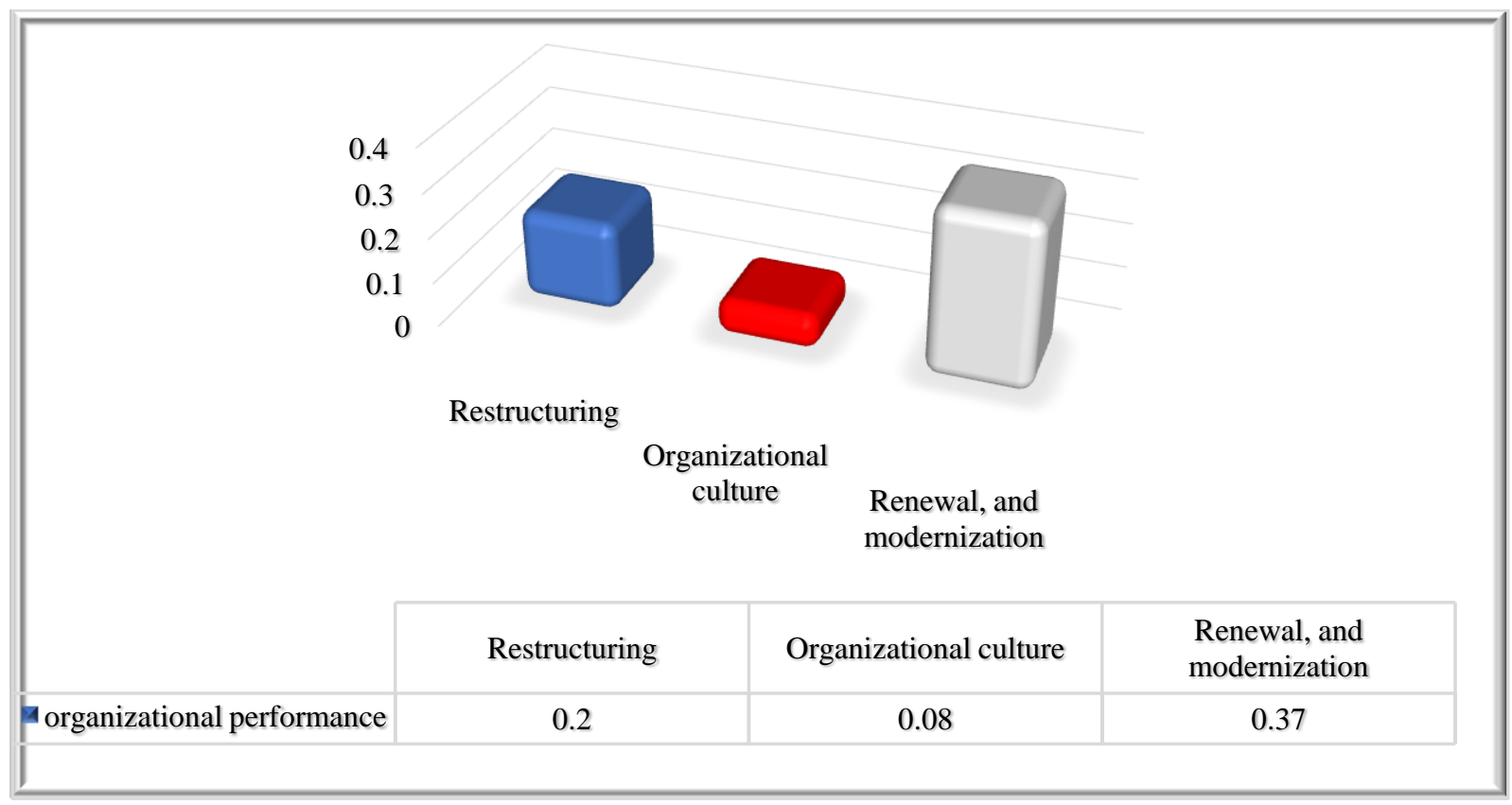

Figure (5) Values $\left(b_{1}\right)$ Multiple Linear Regression Of Strategic Change Approaches

Source: According to (SPSS v. 23) program output 
The results are among the most important stations of the study conducted by the researcher because they represent answers to questions and hypotheses, and the researcher will present the results as they are and in a systematic way.

The conclusions regarding the reality of strategic change in the Oil Projects Company

Statistical results showed that the level of strategic change in the Oil Projects Company (SCOP) is (good), but at the same time it suffers from a decline in certain aspects related to job satisfaction and merger procedures for departments of similar work nature, and as the results showed the company's lack of strategic plans to sense developments In the market, the company's management's level of interest in aspects related to creativity and process development has declined.

The Conclusions regarding the reality of organizational performance in the Oil Projects Company.

In general, the statistical results of the answers of the research sample showed that the level of organizational performance in the Oil Projects Company (good), however, it suffers from a low level of coordination between the administration and departments with regard to investing resources, weak ability to use advanced technologies, and low company ability to obtain resources and expand The size of the workforce, in addition to the methods used by the company's management at work is incompatible with the objectives outlined in the plans and strategies, and a decline in the company's operations that contribute to providing effective outputs compared to the inputs.

The conclusions regarding the relationship between strategic change and organizational performance

Correlation coefficient values showed that the relationship of strategic change with organizational performance is positive, and this means that the more the management of the company becomes interested in strategic change, the greater its ability to improve its level of performance and achieve efficiency and effectiveness.

\section{The conclusions regarding the effect of strategic change in organizational performance}

In general, the statistical values of simple linear regression showed that there is a positive effect of strategic change in organizational performance. As for the strategic change approach, the statistical results of the multiple linear regression showed that the procedures followed by the management of the Oil Projects Company (SCOP) in the restructuring approach are the least impact on organizational performance, which requires a level of attention more.

\section{4-2 Recommendations}

1. Consolidate the relationship between employees and management by providing discussion

Opportunities in matters related to jobs and company activities, listening to their opinions

And participating in decision-making.

2. Make an amendment to the administrative policies used that cause conflicts between

Individuals within the company

3. Setting plans and procedures for assuming managerial positions and investing the

Competencies in appropriate magazines, as they represent an important strategic resource for The Company.

4. Harnessing the company's resources and energies in order to face the rapid developments

Through adopting policies that support renewal and modernization.

5. An update of the methods used for work in order to invest time better in responding to

Customer requirements.

6. Prepare monthly reports regarding the accomplishments of each department and who manages Jobs and submit them to senior management in order to know that every employee is a source of effective performance.

7. Provide instructions and advice that support outstanding performance, diagnose problems at work, and find ways to address them.

8. Define and adhere to employee roles, provided that the tasks are defined in a period of time.

9. Investing the time taken to accomplish tasks by simplifying procedures.

10. Investing human resources in an experienced company and enhancing its ability to use advanced technologies.

11. Study the efficiency of the equipment and devices used, their technical condition, and the Possibility of using them to build a financial outlook to know its ability to invest resources. 
12. Good planning and organization in the exploitation of resources to complete the Implementation process within specified times.

13. Improve the company's ability to obtain financial resources, raw materials, human resources, and advanced technology and use them in activities and jobs to achieve effective Performance.

14. Carry out development of internal activities and processes in line with the goals set in light of Strategic plans.

\section{4-2 The proposals}

1. Intensifying efforts in the field of studies related to strategic change in light of the reality experienced by public sector organizations in the Iraqi environment.
2. Create a department that takes care of the creative work and innovations that are based on

Scientific research and evaluate it through cooperation with Iraqi universities.

3. Conducting more scientific studies looking at achieving efficiency and effectiveness in Iraqi

Government organizations through strategic approaches to change.

\section{REFERENCES}

\section{$\underline{\text { A: Books }}$}

1. Gibbons, Paul, (2015), "The Science of Successful Organizational Change : How Leaders Set Strategy, Change Behavior, and Create an Agile Culture", 1st ed, Publisher, Paul Boger, USA.

2. Norris, D. M. \& Poulton, N. 1.(2010), “A Guide to Planning for Change”,Scup Green Publication, Society for College and University Planning, USA.

3. Norris, D. M. \& Poulton, N. 1.(2010), “A Guide to Planning for Change”,Scup Green Publication, Society for College and University Planning, USA.

4. Alvesson, M. \& Sveningsson, S. (2008), “ Changing Organizational Culture Cultural change work in progress", 1 st ed, Routledge Taylor \& Francis group, USA.

5. Hill, C.W., Jones, G.R. \& Schilling, M.A. (2014), “Strategic Management theory”, 11th ed, Cengage Learning, USA.

\section{B: Journals}

6. Mc-Elroy,William, (1996), "Implementing strategic change through projects",- International Journal of Project Management, Vol. 14, No. 6, pp: 325-329.

7. Muscalu, E, (2014), “ organizational culture change in the organization" Revista academiei fortelor Terestre, Nr, (4)76, pp: 392- 396.

8. Maull, R, Brown, p \& Cliffe, P, (2001), “Organizational Culture and Quality Improvement”. International Journal of Operations and Production Management. Vol.21 No.3. pp: 1-16.

9. Barsade, S. \& Bernstein, J.F. (2016), "Five steps for managing cultural change", University of Pennsylvania, The Wharton School, pp: 1-3.

10. Som, Ashok, (2002), "Building Sustainable Organizations through Restructuring: Role of Organizational Character in France and India", Research Paper, Avenue Bernard Hirsch - B.P.105, 95021 Cergy Pontoise Cedex, France.

11. Harwood, I., Nakola , J. \& Nyaana, D.(2016) “ Effects Of Organizational Restructuring On Firm performance : A Case Of National Bank Of Kenya", Global journal of advanced research, Vol.3, Issue.1 pp: 43-4

12. Kurgat, Agnes, (2016), “ Organizational restructuring: an opportunity for social network and growth", International Journal of Economics, Commerce and Management, Vol 4, Issue 8, pp: 626-655.

13. Sharma,P. \& Chrisman, J.(1999), "Toward a Reconciliation of the Definitional Issues in the Field of Corporate Entrepreneurship", Entrepreneurship Theory and Practice, Vol. 23, Iss.3, pp.11-27. 
14. Ahuja, G. \& Lampert, C.M. (2001), "Entrepreneurship in the Large Corporation: A Longitudinal Study of How Established Firms Create Breakthrough Inventions”, Strategic Management Journal, Vol. 22, pp: 521 - 543.

15. Rosler, Philip,(2015): “Collaborative Innovation Transforming Business Driving Growth", In collaboration with A.T. Kearney and IMP3rove -European Innovation Management Academy.

16. Elena-iuliana, I. \& Maria, C. (2016), “ Organizational performance - A concept that self- seeks to find itself”, Annals of the „Constantin Brâncuși” University of Târgu Jiu, Economy Series, Issue (4), pp: 179-183.

17. Gavrea, C., Ilies, L. \& Stegerean, R. (2011), "Determinants of Organizational performance: the case of Romania", Management \& Marketing Challenges for the Knowledge Society, Vol. 6, No. 2, pp. 285-300.

18. Miller, K, \& Bromily Philip (1990) "Strategic Risk and Corporate Performance: an Analysis of Alternative Risk Measures", Academy of Management Journal, Vol. 30, No. 4, pp: 756-779.

19. Hookana, Heli, (2011), "Measuring of Efficieness, Efficiency and Quality in Public Sector Services - Interventionist Impirical Investigations", MIC2011, Proceedings of the 12th Management International Conference, University of Turku, School of Economics, Finland.

20. Mihaiu, D.M., Opreana, A. \& Cristescu, M.P.(2010), "Efficiency, effectiveness and performance of the public sector", Romanian Journal of Economic Forecasting, (4), pp:132-147.

21. Love, P. \& Skitmore, M. (1996), “Approaches to organisational effectiveness and their application to Construction organization", A paper to be submitted to the ARCOM conf, Sheffield Hallam University, UK, pp: 1-10.

22. Bartuseviciene, I. \& Sakalyte, E. (2013), “Organizational Assessment: effectiveness versus effectiveness", Social Transformations in Contemporary Society, (1), pp: 45-53.

23. Gitonga, E. M. (2014), "The Effects of strategic change on organization performance: A case study of Kapital markets authority, Kenya", Strategic Journal of Business \& Change Management, Vol. 2 (3), pp: $37-51$.

24. Atieno, L. A. \& Kyongo, J. K.(2017), "Effect of strategic change on institutional performance", International Journal of Economics, Commerce and Management, United Kingdom, Vol. V, Issue 7, pp: 596-606.

25. Abdi Khadid, M. \& Rotich, G. (2017), “ Effects of strategic change on performance of commercial banks In Nairobi central business, Strategic", Journal of Business \& Change Management, Vol. 4, Iss. 1 (9), pp 185 - 200.

\section{C- Thesises}

26. Shin, Kilho, (2019), “The Time Dimension in Strategic Change and Firm Performance: The South Korean Context" PhD thesis in Philosophy, University of Texas at Arlington.

27. Kamau, R. G. ( 2013 ), "The relationship between strategic change and the Organizational performance of large printing Firms in Nairobi Kenya", Master Thesis, School of Business, University of Nairobi.

28. Kusar,M.T.(2010), “The Development And Renewal Of Strategic Capabilities”, PhD Thesis 1 in Philosophy In the Robin son College of Business Of Georgia State University.

29. Kamau, R. G. ( 2013 ), "The relationship between strategic change and the Organizational performance of large printing Firms in Nairobi Kenya",Master Thesis, School of Business, University of Nairobi. 